\title{
EXPLORING HUBRIS IN PHYSICIANS: ARE THERE EMOTIONAL CORRELATES?
}

\author{
Vaitsa Giannouli \\ Bulgarian Academy of Sciences, Sofia, Bulgaria \\ received: 2.10.2020; \\ revised: 22.11.2020; \\ accepted: 2.12 .2020

\begin{abstract}
SUMMARY
Are there emotional correlates of hubristic symptomatology in physicians working in state hospitals at intrapersonal and interpersonal levels? 188 physicians completed a series of questionnaires related to emotional aspects and a 5-point Likert scale examining hubris. Their patients responded to a satisfaction question. Results revealed that years of working experience and negative affect correlate negatively with hubris, while Others' Emotion Appraisal and Regulation of Emotion correlate positively. Patients seem not to report different levels of personal satisfaction from the provided healthcare services, based on the emotional characteristics and the hubris levels of their physician. Only work experience predicted hubris self-reported symptoms.
\end{abstract}

Key words: hubris - emotions - physicians

\section{INTRODUCTION}

Individuals who are successful in their life can be inflicted by excessive pride and self-confidence, and the manifestations of such behaviours may demonstrate noticeable signs of narcissism and on extreme cases, hubris (Diamandis \& Bouras 2018). Hubris has been proposed as a syndrome that includes exaggerated pride, over-whelming self-confidence, and contempt exhibited to others (Owen 2006). Recently, researchers have pointed to the importance of examining leaders' hubristic behavior in organizations as they not only influence their colleagues but also healthcare workers behavior may influence the doctor-patient relationship (Owen \& Davidson 2009), but still there is scarce research examining hubris in medical settings, and more specifically in physicians working in hospitals (Giannouli 2017). The aim of this pilot research is to examine hubris at an intra-and-inter-individual level with the use of a new self-report questionnaire in physicians in Greece, while the influence of diverse emotional factors is also examined. In addition to that, patient satisfaction is measured in order to provide a research-based response to a recently published theoretical approach regarding the role of hubris as a missing variable in pandemic preparedness and its possible outcomes on COVID-19 management (Lincoln 2020).

\section{METHODS}

The sample of this research consisted of 188 physicians (119 males) who worked at the time of the administration of the questionnaires in healthcare centers in Greece. Their average age was $44.36 \quad(\mathrm{SD}=11.94)$ years, their average working experience as physicians were $14.41(\mathrm{SD}=12.75)$ years, 140 had a university medical degree, 33 had a master's degree, and 15 had a $\mathrm{PhD}$, while 48 did not have a family-partner, 127 were married and/or had a family, 9 were divorced, and 4 were widowers.

Study inclusion criteria were three: 1) being a physician, 2) being a native Greek speaker, 3) being free of a formal diagnosis of psychiatric disorder, 4) agreeing to complete all questionnaires, and 5) having a minimum of one year working experience and currently working in a state hospital, as the aim of the study focused only on public and not private healthcare settings.

Participants completed anonymously a number of questionnaires which examine different aspects of emotions: 1) Job Affect Scale - 17 questions 5 ( $\alpha=0.88$ for positive and $\alpha=0.77$ for negative subscales), 2) Emotional Labour Scale - 6 questions $6(\alpha=0.88$ for surface acting and $\alpha=0.80$ for deep acting), 3) Emotion Regulation Questionnaire - 10 questions $7(\alpha=0.92$ for reappraisal and $\alpha=0.84$ for suppression subscales), 4) Generalized Immediacy Scale - 4 questions $8(\alpha=0.85)$, 5) General Index of Job Satisfaction - 12 questions 9-10 $(\alpha=0.91), 6)$ Maslach Burnout Inventory - 22 questions $11(\alpha=0.88), 7)$ Wong-Law Emotional Intelligence Scale - 16 questions 12-13 ( $\alpha$ Self-Emotion Appraisal =0.90, $\alpha$ Others' Emotion Appraisal $=0.92, \alpha$ Use of Emotion $=$ $0.86, \alpha$ Regulation of Emotion $=0.86), 8$ ) State Anxiety Inventory form $X-40$ questions $14(\alpha=0.92), 9)$ and Perceived Cohesion Scale - 6 questions 15-16 $(\alpha=0.95)$.

One more questionnaire based on the proposed symptoms of hubris syndrome as described by Owen and Davidson3 was administered in the form of 14 questions $(\alpha=0.805)$ on a 5-point Likert scale (1strongly disagree to 5-strongly agree) (see Means and SDs per question in Table 1). All 10 questionnaires were completed by the participants in their own place and without a time limitation. 
For each physician, a patient responded to a single 5point Likert scale question regarding their satisfaction from the services provided by the physician (the choice of a single question was made upon the time limitations of completing questionnaires during medical visits at healthcare institutions). The demographics of the patients were 188 patients with various healthcare problems, $\mathrm{M}_{\text {age }}=68.64(\mathrm{SD}=8.17), \mathrm{M}_{\text {education years }}=9.01, \mathrm{SD}=4.35$.

Data was analyzed using SPSS Version 22.0 for Windows. Pearson correlations were performed between hubris total score and the total scores of the 'emotion' scales and their subscales. In addition to that, correlations were sought for hubris total score for the physician and the single question that their patients responded. Regression analyses were performed with hubris total score as the dependent variable and the aforementioned emotion questionnaires and the demographics (age, education, gender, family status, and working experience) as independent variables.

\section{RESULTS}

Pearson correlations between the total score of hubris and all the above mentioned emotional variables revealed that there are statistically significant negative correlations of hubris with time of work experience in years $(\mathrm{r}=-0.178, \mathrm{p}=0.016)$ and hubris with negative affect $(r=-0.213, p=0.004)$, while statistically significant positive correlations were found for hubris with Others' Emotion Appraisal $(\mathrm{r}=0.151, \mathrm{p}=0.045)$ and hubris with Regulation of Emotion ( $\mathrm{r}=0.151, \mathrm{p}=0.045)$. No statistically significant correlation was found between hubris total score for the physician and the single satisfaction question answered by their patients. Regression analyses revealed that only work time predicted hubris reported symptoms $(B=-0.061$, Beta $=-0.165, \mathrm{p}=0.031$ ).

Table 1. Responses regarding hubris on a 5-point Likert scale

\begin{tabular}{|c|c|c|c|c|}
\hline Questions & $\begin{array}{l}\text { Minimum } \\
\text { score }\end{array}$ & $\begin{array}{l}\text { Maximum } \\
\text { score }\end{array}$ & Mean & SD \\
\hline $\begin{array}{l}\text { 1. Do you believe that you see the world primarily as an arena in which } \\
\text { to exercise power and seek glory? }\end{array}$ & 1 & 4 & 1.90 & 0.71 \\
\hline $\begin{array}{l}\text { 2. Do you believe that you have a predisposition to take actions which } \\
\text { seem likely to cast the individual in a good light - i.e. in order to } \\
\text { enhance image? }\end{array}$ & 1 & 3 & 1.20 & 0.41 \\
\hline $\begin{array}{l}\text { 3. Do you believe that you have a disproportionate concern with image } \\
\text { and presentation? }\end{array}$ & 1 & 3 & 1.88 & 0.48 \\
\hline $\begin{array}{l}\text { 4. Do you believe that you have a messianic manner of talking about } \\
\text { current activities and a tendency to exaltation? }\end{array}$ & 1 & 3 & 1.63 & 0.66 \\
\hline $\begin{array}{l}\text { 5. Do you believe that you have an identification with the nation, or } \\
\text { organization to the extent that you regards your outlook } \\
\text { and interests as identical? }\end{array}$ & 1 & 5 & 1.75 & 0.66 \\
\hline $\begin{array}{l}\text { 6. Do you believe that you have a tendency to speak in the third person } \\
\text { or use the royal 'we'? }\end{array}$ & 1 & 2 & 1.62 & 0.48 \\
\hline $\begin{array}{l}\text { 7. Do you believe that you have an excessive confidence in your own } \\
\text { judgement and contempt for the advice or criticism of others? }\end{array}$ & 1 & 3 & 1.81 & 0.64 \\
\hline $\begin{array}{l}\text { 8. Do you believe that you have an exaggerated self-belief, bordering } \\
\text { on a sense of omnipotence, in what you personally can achieve? }\end{array}$ & 1 & 4 & 1.56 & 0.67 \\
\hline $\begin{array}{l}\text { 9. Do you believe that you have a belief that rather than being } \\
\text { accountable to the mundane court of colleagues or public opinion, } \\
\text { the court to which you answer is: History or God? }\end{array}$ & 1 & 3 & 1.49 & 0.57 \\
\hline $\begin{array}{l}\text { 10. Do you believe that you have an unshakable belief that in that court } \\
\text { you will be vindicated? }\end{array}$ & 1 & 3 & 1.77 & 0.65 \\
\hline $\begin{array}{l}\text { 11. Do you believe that you have loss of contact with reality; often } \\
\text { associated with progressive isolation? }\end{array}$ & 1 & 5 & 1.93 & 0.77 \\
\hline $\begin{array}{l}\text { 12. Do you believe that you have restlessness, recklessness and } \\
\text { impulsiveness? }\end{array}$ & 1 & 5 & 1.59 & 0.65 \\
\hline $\begin{array}{l}\text { 13. Do you believe that you have a tendency to allow your 'broad } \\
\text { vision', about the moral rectitude of a proposed course, to obviate } \\
\text { the need to consider practicality, cost or outcomes? }\end{array}$ & 1 & 5 & 1.94 & 0.71 \\
\hline $\begin{array}{l}\text { 14. Do you believe that things go wrong because too much self-confi- } \\
\text { dence has led you not to worry about the nuts and bolts of policy? }\end{array}$ & 1 & 3 & 1.44 & 0.56 \\
\hline
\end{tabular}




\section{DISCUSSION}

Hubris in physicians seems to be related to prior years of working experience. The unexpected finding that working experience in a hospital may influence the expressed hubristic symptoms should be further investigated along with other emotional and personality factors. An interesting finding is that patients seem not to report different levels of personal satisfaction from the provided healthcare services, based on the emotional characteristics and the hubris levels of their physician. Self-ratings can provide information not necessarily detected by observers. Although the self-report scales that were used for the measured emotional structures may demonstrate a rather 'distorted picture' of the individual, something that renders the responses of the participants not objective, it is of interest to explore how participants see themselves regarding their hubristic characteristics and how they perceive different aspects of their emotional state.

\section{CONCLUSION}

Despite these limitations, the findings of this study make a novel contribution to the neglected field of hubris by surpassing its strictly political connotations (Jakovljević 2011), through the exploration of hubris in healthcare from the viewpoint not only of the physicians, but also of their patients. Future research may explore hubris in different cultural contexts and in larger samples of different types of healthcare professionals (e.g. nurses, psychologists etc.), while 'leader-subor- dinate' multilevel analyses could reveal how these selfreported tendencies are experienced at a interindividual level by different groups of employees in healthcare settings.

\section{Acknowledgments:}

Role of funding sources : Funding sources had no role in study design or in the collection, analysis and interpretation of data; or in the writing of this report.

Conflict of interest: None to declare.

\section{References}

1. Diamandis EP \& Bouras N: Hubris and Sciences. F1000Res 2018; 7

2. Giannouli V: What do we really know about hubris, culture and health professionals in leadership positions? A methodological recommendation. Asian J Psychiatr 2017; 26:150-151

3. Jakovljević M: Hubris syndrome and a new perspective on political psychiatry: need to protect prosocial behavior, public benefit and safety of our civilisation. Psychiatr Danub 2011; 23:136-138

4. Lincoln M: Study the role of hubris in nations' COVID-19 response. Nature 2020; 585:325

5. Owen D: Hubris and nemesis in heads of government. $J R$ Soc Med 2006; 99:548-51

6. Owen D \& Davidson J: Hubris syndrome: An acquired personality disorder? A study of US Presidents and UK Prime Ministers over the last 100 years. Brain 2009; 132:1396-1406

\section{Correspondence:}

Vaitsa Giannouli, PhD

Institute of Neurobiology, Bulgarian Academy of Sciences Acad. G. Bonchev str., bl. 23, 1113 Sofia, Bulgaria

E-mail: giannouliv@hotmail.com 